\title{
ANALYSIS OF DROUGHT-FLOOD ABRUPT ALTERNATION OF TOBACCO BASED ON PRECIPITATION AND SOIL PONDING IN SIUWEN CHINA
}

\author{
ZHANG, Z. Z. ${ }^{1}-$ YUAN, Y. J. ${ }^{1 *}-$ SHEN, D. F. ${ }^{2}-$ FAN, H. ${ }^{1}$ \\ ${ }^{1}$ School of water conservancy engineering, North China University of Water Resources and \\ Electric Power, Zhengzhou 450046, China \\ ${ }^{2}$ Guizhou Water Conservancy Research Institute, Guiyang 550002, China \\ ${ }^{*}$ Corresponding author \\ e-mail:534012813@qq.com
}

(Received $3^{\text {rd }}$ May 2019; accepted $11^{\text {th }}$ Jul 2019)

\begin{abstract}
Drought-flood abrupt alternation disaster caused by climate change results in greater difficulty in disaster relief and more serious agricultural losses. In order to identify the characteristics of drought-flood abrupt alternation in the tobacco growth period and effectively prevent and reduce the drought-flood abrupt alternation disaster, the daily precipitation data in the tobacco growth period from 1951 to 2017 in Guiyang City are used and the data of soil moisture content in the Xiuwen country Irrigation Test Base of Guizhou Irrigation Test Center are adopted. By defining continuous days without available precipitation and the cumulative available precipitation during the flood period, the characteristics of drought-flood abrupt alternation in Guiyang are comprehensively analyzed. The results are as follows: (1) it can be verified by soil moisture content data that the law of drought-flood abrupt alternation in tobacco growth period can be accurately described based on continuous days without available precipitation and the cumulative available precipitation during the flood period. (2) In the tobacco growth period, there are two or more times of drought-flood abrupt alternation with low intensity. (3) In tobacco root extension period, there is no drought-flood abrupt alternation; during the flourishing growing period of tobacco, drought-flood abrupt alternation with low intensity prevails, and the intensity and frequency of drought-flood abrupt alternation increase; in tobacco mature period, the intensity of drought-flood abrupt alternation fluctuates greatly, and the intensity and frequency of drought-flood abrupt alternation increase. The research results can provide theoretical basis for the formulation of tobacco disaster prevention and mitigation countermeasures in Guiyang China.

Keywords: climate change, drought-flood abrupt alternation disaster, continuous days without available precipitation, accumulative available precipitation during flood period, tobacco, Guiyang City
\end{abstract}

\section{Introduction}

The IPCC's fifth assessment report points out that the global warming has been no longer in question (IPCC, 2013). Extreme climate events such as torrential rain, flood, high temperature and drought caused by climate change frequently occur in the world, which has attracted wide attention of scholars both at home and abroad (Mesmoudi et al., 2017; Nocera et al., 2017; Scafetta et al., 2017; Bello and Mamman, 2018; Kong, 2018; Magrini et al., 2018; Zhao et al., 2018; Uttam et al., 2018; Dittus et al., 2018).

Tobacco is an important economic crop in Guiyang. Guiyang has a long history of flue-cured tobacco planting, and the quality of tobacco leaves is better. In 2017, the city planted 13,700 hectares of flue-cured tobacco, and acquired 16,700 tons of flue-cured tobacco, with $36.72 \%$ of fine tobacco and $96.70 \%$ of medium tobacco. Tobacco industry is the dominant traditional industry in Guiyang and plays an important role in local economic construction. However, due to the influence of special karst landform and the continuous occurrence of Nino phenomenon (ElNino) in recent years, the spatial 
and temporal distribution of precipitation in Guiyang tobacco area is uneven, drought and flood disasters occur frequently, which seriously threatens the output and quality of tobacco in Guiyang. Therefore, it is necessary to study the characteristics of droughtflood abrupt alternation in Guiyang tobacco area so as to provide scientific basis for disaster prevention and reduction.

Drought-flood abrupt alternation refers to the meteorological and hydrological events in which there is no precipitation or little precipitation in the early period and the drought has occurred, and then high-intensity precipitation and flood occurs in a short period (Huang, 2015). Many scholars in China have made in-depth study on droughtflood abrupt alternation from different points of view. Wu et al. (2006) first define a summer long-cycle drought-flood abrupt alteration index (LDFAI). On the basis of this, most of the scholars study the space-time evolvement law of drought-flood abrupt alternation in different areas (Shan et al., 2015; He et al., 2016; Liu et al., 2017; Peng et al., 2018). If LDFAI is used to study the law of drought-flood abrupt alternation in tobacco growth period, this only considers the difference of drought and flood in the early and late period and the time scale is too large. The drought-flood abrupt alternation degree can be evaluated only after the end of the whole growing period of tobacco, which is unable to meet the needs of real-time monitoring and early warning assessment. Based on LDFAI, the dry-wet abrupt alteration index (DWAAI) is constructed, which can well reflect the abrupt alternation degree. According to the theory, there is only one time of drought-flood abrupt alteration in a year, and the date of abrupt alteration is the day when the value of DWAAI is the highest. In fact, the tobacco growth period is also the season of frequent occurrence of drought and flood in Guiyang. Thus, DWAAI can't be used to study the evolvement law of drought-flood abrupt alternation in tobacco growth period because there may be two or more times of drought-flood abrupt alteration.

The analysis of drought in continuous days without precipitation from the point of view of daily precipitation can make drought monitoring and assessment more precise on time scale (Jiang et al., 2009; Wang et al., 2014; Gu, 2014; Shan et al., 2015), the application is more mature, and is determined as local standard in Gansu and Guizhou (Gansu provincial bureau of quality and technical supervision, 2011; Guizhou provincial bureau of quality and technology supervision, 2015). However, the index of continuous days without available precipitation is considered only in the sense of meteorology. In fact, precipitation can be used by crops only if it reaches a certain level, so the effectiveness of precipitation should be considered. Huang et al. (2014) improve continuous days without available precipitation, considering that the continuous days without available precipitation can integrate both precipitation and precipitation days, and indirectly reflect the income and expenditure of farmland precipitation and profit and loss of soil moisture. Flood disaster of crops is not only directly affected by excessive and concentrated precipitation, but also closely related to soil texture, light conditions, crop species and their developmental stages (Huo and Wang, 2009). Yang et al. (2017) put forward the concept of "equivalent precipitation" that represents the cumulative effect of precipitation in the early period and current process on flood. Based on this, the grade index of spring corn flood is constructed. In consideration of the cumulative effect of precipitation on flood process, Fan (2018) constructs the catastrophic index of oilseed rape flood process by taking the effective cumulative precipitation and the number of rainy days as the cause of flood disaster. 
During the study of drought period of drought-flood abrupt alteration, continuous days without available precipitation are used as the drought index of tobacco in order to analyze the drought characteristics of tobacco in different growing periods from the daily dynamic perspective. The formation process of tobacco flood can be objectively and quantitatively characterized by the classification of flood grades by accumulative available precipitation in flood period. Based on this, this study explores the evolvement law of drought-flood abrupt alteration in tobacco growth period, which can provide scientific and technical support for timely and accurate evaluation of the impact of drought-flood abrupt alteration on tobacco growth and realize flood control, drought resistance, high and stable yield and evaluation of disaster reduction benefits of water conservancy projects.

\section{Materials and methods}

\section{Data sources}

The data are the daily precipitation data of Guiyang National Standard Meteorological Station from 1951 to 2017 provided by the National Meteorological Information Center, and soil moisture content data the No. 2 test pit of Xiuwen country Irrigation Test Base of Guizhou Irrigation Test Center in 2015 and 2016 in China.

\section{Overview of the study area}

Guiyang City, located in the east of Yunnan-Guizhou Plateau and the central part of Guizhou Province, is an important central city in southwest China in Figure 1.

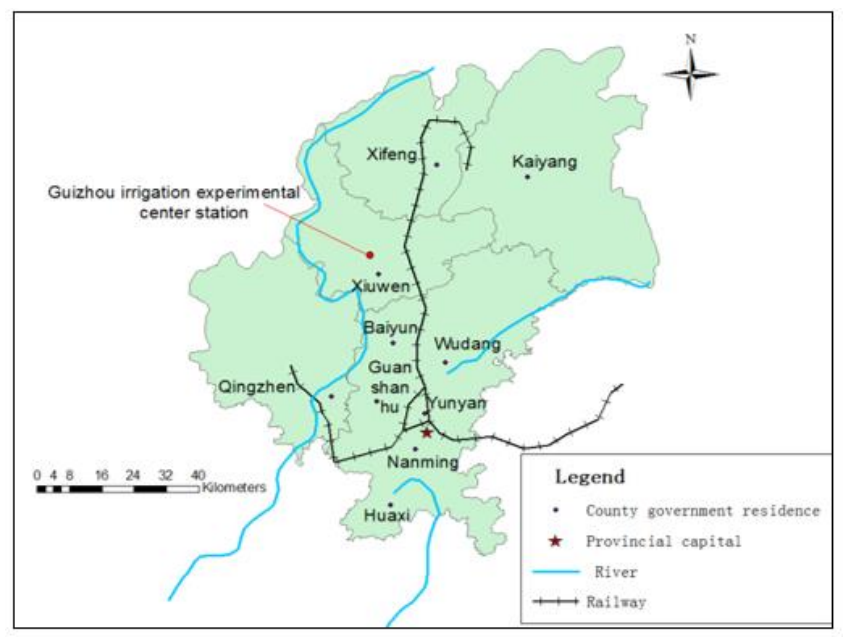

Figure 1. Overview of the study area

Guiyang city has a total area of 8,034 square kilometers and an area for tobacco cultivation, planted 13,700 hectares of flue-cured tobacco. With the altitude of around $1,100 \mathrm{~m}$, it is located in the Federl circulation cell and is controlled by the westerlies all the year round. It belongs to the subtropical humid and mild climate with the annual average total precipitation of about $1,130 \mathrm{~mm}$. The precipitation distribution is uneven. Rainwater is abundant in summer, accounting for about $70 \%$ of the annual precipitation, so that it is easy for drought-flood abrupt alteration to occur. 


\section{Calculation of accumulative available precipitation}

Available precipitation refers to the part of total precipitation that can be preserved in the root layer of crops to meet the needs of crop evapotranspiration, excluding surface runoff and the part that leaks below the water-absorbing layer of crop roots. The main factors affecting available precipitation are precipitation intensity, soil texture and structure, topography and flatness, soil water content before precipitation, crop species and growing period (Guo et al., 2012). Available precipitation calculation formula for a certain precipitation $(\mathrm{Xu}, 2009)$ is:

$$
P_{e \mathrm{i}}=\alpha_{i} P_{i}
$$

where, $P_{i}$ is total precipitation of $i^{\text {th }}$ time of precipitation, $m m ; a_{i}$ is the available utilization coefficient. Considering the factors such as large terrain slope, barren land and unique karst landform in Guiyang, the values of $a_{i}$ are as follows, by combination of the available utilization coefficient of precipitation studied by the scholars (Dastane, 1974; Liu et al., 2009): when $P_{i} \leq 5 \mathrm{~mm}, a_{i}=0$; when $5 \mathrm{~mm} \leq P_{i} \leq 50 \mathrm{~mm}, a_{i}=0.85$; when $P_{i}>50 \mathrm{~mm}, a_{i}=0.85$.

The accumulative available precipitation during the flood period $P_{E}$ is equal to the sum of the multiple time of available precipitation during the flood period, and the calculation formula is as follows:

$$
P_{E}=\sum_{i=1}^{n} P_{e i}
$$

In general, tobacco has certain flood tolerance. Considering the different flood tolerance of tobacco in different growing periods and the different critical values of precipitation in effective process of different growing periods, this study classifies the flood standards of tobacco in different growing periods (Tang, 2011), in Table 1.

Table 1. Classification of tobacco flood grade based on accumulative available precipitation

\begin{tabular}{c|c|c|c|c|c}
\hline \multirow{2}{*}{$\begin{array}{c}\text { Tobacco growth } \\
\text { period }\end{array}$} & $\begin{array}{c}\text { Process effective } \\
\text { precipitation critical } \\
\text { value } \boldsymbol{P}_{\boldsymbol{k}}(\mathbf{m m})\end{array}$ & \multicolumn{4}{|c}{ Grading } \\
\cline { 3 - 6 } & 25 & Light flood & $\begin{array}{c}\text { Moderate } \\
\text { flood }\end{array}$ & Severe flood & Extreme flood \\
\hline $\begin{array}{c}\text { Root extension } \\
\text { stage }\end{array}$ & 25 & $40 \sim 55$ & $55 \sim 70$ & $>85$ \\
$\begin{array}{c}\text { Grow prosperous } \\
\text { stage }\end{array}$ & 35 & $\leq 50$ & $50 \sim 75$ & $75 \sim 100$ & $>125$ \\
pre-mature stage & 25 & $\leq 45$ & $40 \sim 65$ & $65 \sim 85$ & $>105$ \\
mature late stage & 20 & $\leq 40$ & $40 \sim 55$ & $55 \sim 70$ & $>85$ \\
\hline
\end{tabular}

\section{Continuous days without available precipitation}

Continuous days without available precipitation refer to the duration days when the precipitation is less than the available precipitation critical value in the crop growing season. This index combines the precipitation and the precipitation days, but the daily water requirement of the crops is basically close under the non-precipitation 
meteorological conditions. Therefore, the index can indirectly reflect the income and expenditure of farmland precipitation and profit and loss of soil moisture. Combined with the law and actual situation of tobacco water demand in Guiyang (Cai et al., 2005; Cheng, 2006; Gao, 2006), the formula for calculating continuous days without available precipitation is as follows (Huang et al., 2014):

$$
\text { Dnp }=\sum_{j=1}^{m} a \square \operatorname{Dnp}_{j}
$$

where, Dnp is number of continuous days without available precipitation, $d ; a$ is the adjustment coefficient of tobacco in different growing periods and the specific value is shown in Table 2. The calculation formula of $D n p_{j}$ is as follows:

$$
\operatorname{Dnp}_{j}=\left\{\begin{array}{cc}
1 & P_{e i} \leq P_{0} \\
0 & P_{e i}>P_{0} \text { and } P_{n} \leq P_{k} \text { or } P_{e i}>P_{k}
\end{array}\right.
$$

where, $P_{e i}$ is the daily available precipitation, $\mathrm{mm} ; P_{0}$ is the critical value of daily available precipitation, $\mathrm{mm} ; P_{0}$ is $5 \mathrm{~mm}$ during the critical water demand period (flourishing growing period) of tobacco, and is $3 \mathrm{~mm}$ in the rest periods. $P_{n}$ and $P_{k}$ is the process accumulative precipitation, of which $P_{n}$ refers to the accumulation of available precipitation process that can alleviate drought and reach the root layer of crops to be used by crops, $\mathrm{mm} ; P_{k}$ is the critical value of available precipitation, $\mathrm{mm}$. The meaning of Eq. 4 is:

1) When $P_{e i} \leq P_{0}$, that is, the daily precipitation is below the critical value of daily available precipitation, drought occurs or continues, and days without available precipitation are calculated, that is $D n p_{j}=1$;

2) When $P_{e i}>P_{0}$ and $P_{n}<P_{k}$, that is, the daily precipitation forms available precipitation, but the process available precipitation is still insufficient to end the drought, the drought is interrupted but not alleviated and the drought continues after the precipitation process ends, and the drought days don't accumulate, $D n p_{j}=0$;

3) When $P_{e i} \geq P_{0}$, that is, the accumulative precipitation of one effective precipitation process is greater than the critical value of the effective process precipitation, excessive precipitation will be lost in the form of surface runoff, and the drought will continue after the precipitation process ends, and the drought days don't accumulate, $\operatorname{Dnp}_{j}=0$;

\section{Application of Dnp to evaluate multiple drought processes in tobacco growth period}

The tobacco growth period is in the season of frequent drought in Guiyang City, and sometimes there are two or more times of drought, so it is necessary to evaluate the accumulative process of drought in the whole growing period of tobacco. Perfect the Eq. 3 (Huang et al., 2014):

$$
\operatorname{Dnp}=\sum_{i=1}^{n} a \times\left(\sum_{j=1}^{m} \operatorname{Dnp}_{j i}-D_{p j}\right)
$$

where, Dnp is the accumulative continuous days without available precipitation during $n$ times of drought processes in the whole growing period of tobacco; $D n p_{j}$ is 
continuous days without available precipitation in a single drought process, and the meaning is the same as $E q .4 ; n$ is the time of drought in the whole growing period of tobacco; $m$ is the number of day of $j^{\text {th }}$ drought. The meaning and value of $a$ are the same as $E q .3 ; D p j$ is the equivalent days of available precipitation in the process of relieving drought to reduce the drought in the later period of $j^{\text {th }}$ drought in tobacco growth period; $j$ is the time of drought. The calculation formula of $D p j$ is as follows:

$$
D p j=P_{n j} / 2 P_{0}
$$

where, $P_{n j}$ is accumulative available precipitation in the course of a drought mitigation when $P_{n} \geq P_{k}, \mathrm{~mm}$, the calculation process of $P_{n j}$ is the same as $E q$. 2. The result of the calculation of $D p j$ is taken as an integer. The meaning of $P_{0}$ is the same as Eq. 4 . According to the previous calculation result of crop water demand (Tang, 2011), the daily water demand of tobacco $E T_{c}$ is close to the critical value $P_{0}$ of available precipitation and can be approximately equal. Therefore, the meaning of the Equations (5)-(6) is that the drought can compensate for the drought in the later period of available precipitation. In the process of interrupting the drought, if the precipitation is excessive in a single day, the excessive precipitation will be lost in the form of surface runoff, and the drought can't be relieved.

According to previous research result of available precipitation and the characteristics of tobacco water demand in Guizhou (Tang, 2011), the specific $P_{k}$ vales be included in the Table 1 . The values of $P_{0}, P_{k}$ and $a$ are subdivided and adjust according to the tobacco growth period. $P_{0}$ is $4 \mathrm{~mm}$ in the root extension period and the pre-mature period, $5 \mathrm{~mm}$ in the flourishing growing period, and $3 \mathrm{~mm}$ in the pre-mature period. Please refer to the table for the specific values of $P_{k} . a$ is 1.1 in the root extension stage and the post-mature period, 1.3 and 1.2 in the flourishing growing period and the pre-mature period respectively. The days without available precipitation in a single drought process is calculated according to Eq. 3 and Eq. 4. When the continuous days without available precipitation reaches above $10 d$, it is determined as a drought process, and the specific classification is shown in Table 2.

Table 2. Criteria for tobacco drought grades based on continuous days without available precipitation

\begin{tabular}{c|c|c|c|c|c}
\hline Drought grade & Normal & $\begin{array}{c}\text { Light } \\
\text { drought }\end{array}$ & $\begin{array}{c}\text { Moderate } \\
\text { drought }\end{array}$ & $\begin{array}{c}\text { Severe } \\
\text { drought }\end{array}$ & $\begin{array}{c}\text { Extreme } \\
\text { drought }\end{array}$ \\
\hline $\begin{array}{c}\text { continuous days } \\
\text { without available precipitation }\end{array}$ & $\leq 10$ & $10 \sim 20$ & $20 \sim 30$ & $30 \sim 45$ & $>45$ \\
\hline
\end{tabular}

According to the local agricultural production experience in Guizhou, the tobacco transplanting period is in the first ten-day period of May. Assuming that the transplanting is completed on May 10 and the soil moisture is sufficient, and the drought start date is counted from May 11; if the start day is rainy, the first rain-free day after the end of the precipitation process is taken as the drought start date; if the start day is a rain-free day, this day is the start day of the drought. 


\section{Results and analysis}

\section{Analysis on the evolvement law of drought-flood abrupt alternation during the tobacco growth period}

In accordance with the daily precipitation data in Guiyang from May to August of 1951, the daily available precipitation $P_{e i}$ is calculated by the $E q .1$, and the accumulative available precipitation in different periods is calculated by the Eq. 2 . Eqs. 3-6 are used to calculate continuous days without available precipitation to study evolvement process of drought-flood abrupt alternation during the tobacco growth period.

Figure 2 describes the evolvement law of drought-flood abrupt alternation during the tobacco growth period. In a short period of two weeks after tobacco transplanting, the accumulative available precipitation reaches more than $90 \mathrm{~mm}$. At this time, it is tobacco root extension period when the daily average water demand is $3 \mathrm{~mm}$, so serious flood disaster occurs at this period.

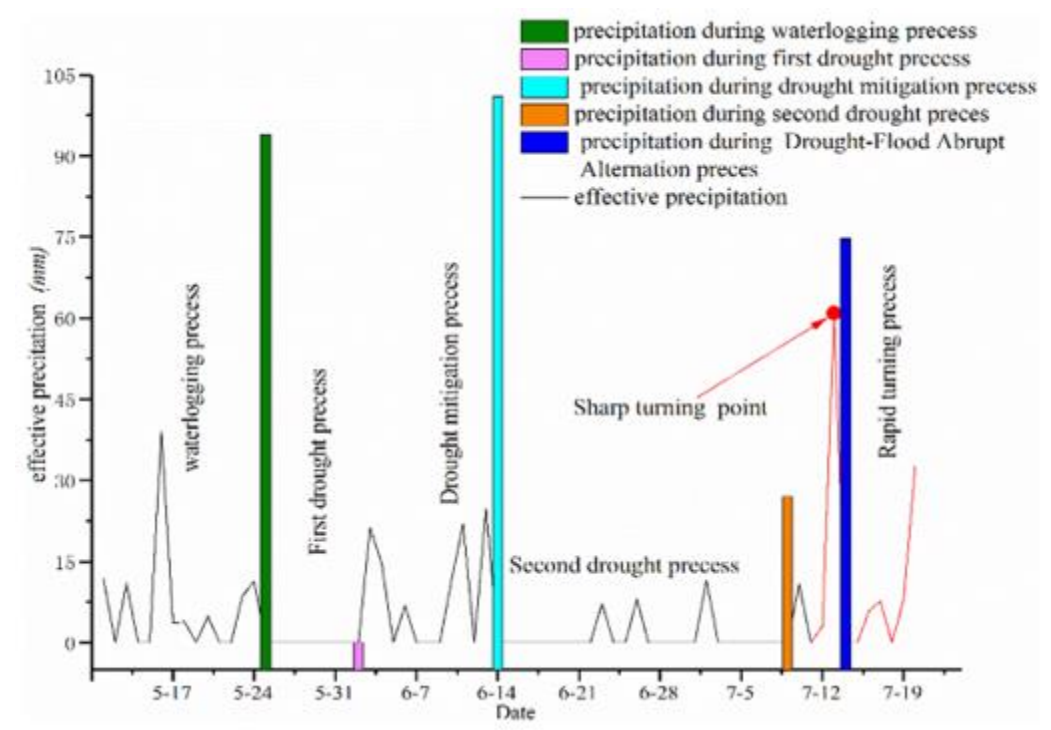

Figure 2. Evolvement process of drought-flood abrupt alternation during the tobacco growth period

During the next week, there is no available precipitation and belongs to light drought. In the following two weeks, the total available precipitation is as high as $100 \mathrm{~mm}$. Because there is a light drought process in the early period, this precipitation can alleviate the drought in the early period. At this time, the tobacco is in the flourishing growing period and the daily average water demand is large, so there is no flood disaster. From June 14 to July 10, the accumulative available precipitation is less than $30 \mathrm{~mm}$ while it is the critical period of tobacco water demand and the daily average water demand is more than $5 \mathrm{~mm}$. The water shortage will seriously affect the output and quality of tobacco. The Dnp value is calculated to be 28 days, belonging to moderate drought. From July 10 to July 13, in a short period of 3 days, the accumulative available precipitation is more than $70 \mathrm{~mm}$, and drought-flood abrupt alternation occurs. The intensity turns from moderate drought to moderate flood, and the point of droughtflood abrupt alternation is on July 13. 
In order to verify the feasibility of the research method, the soil moisture content and precipitation data of No. 2 test pit of Xiuwen Irrigation Test Base of Guizhou Irrigation Test Center from May 1 to August 31, 2016 are selected in this study. The variation law between precipitation and soil moisture content is studied and described in detail in Figure 3.

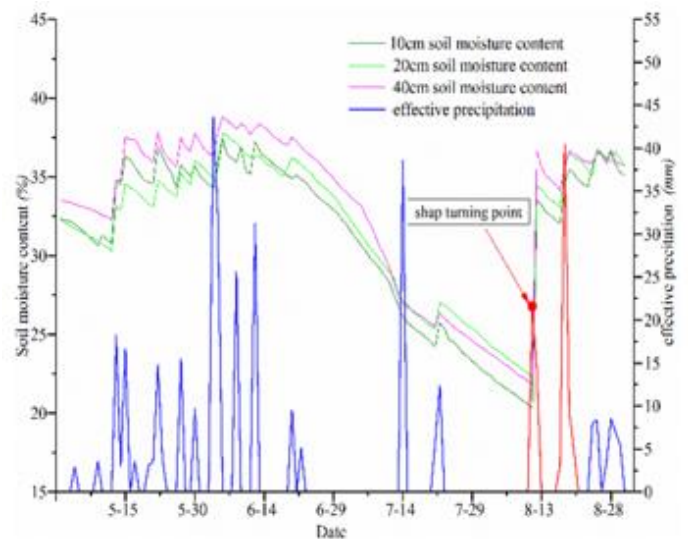

(a) 2015

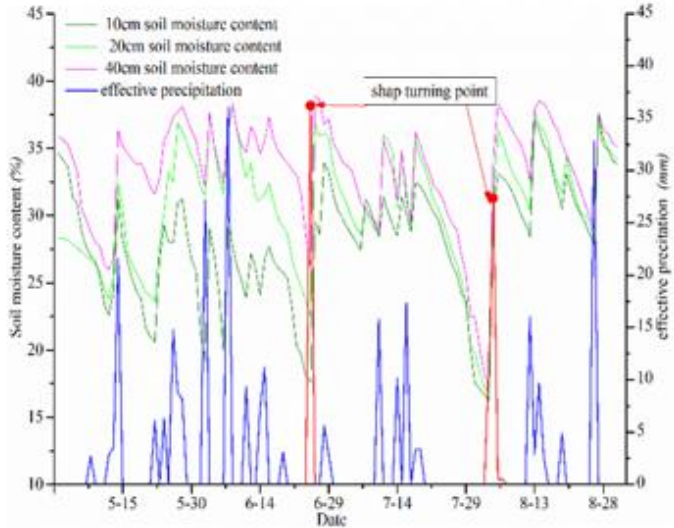

(b) 2016

Figure 3. Variation Law between Precipitation and Soil Moisture in the Irrigation Experimental Station of Xiuwen County in 2015 and 2016

Li et al. (2007) hold that during the whole growing period of flue-cured tobacco, the soil moisture should be maintained at $60 \%-68 \%, 78.5 \%-81 \%, 76 \%-78 \%$ of the field water holding capacity during the root extension period, flourishing growth period and mature period, respectively, which is most beneficial to the growth and development of flue-cured tobacco. It can be seen from Figure $3 a$ that during the root extension period of tobacco in 2015, 5 times of available precipitation are more than $10 \mathrm{~mm}$ and soil moisture content is more than $80 \%$ of the field water holding capacity. Han et al. (1992) hold that too high soil moisture is unfavorable for root development during the root extension period of tobacco and that total absorption area and active absorption area of root all decrease, so tobacco is subjected to flood stress at this period. In the flourishing growth period of tobacco, 3 times of available precipitation exceed $20 \mathrm{~mm}$ and the soil moisture content is more than $80 \%$ of the field water holding capacity. The soil moisture content at this time is beneficial to the growth and development of tobacco and the formation of output and quality because the flourishing growth period is critical for tobacco water demand. In the pre-mature period, there is a precipitation of more than $35 \mathrm{~mm}$. Guiyang City belongs to typical karst landform, the surface water leakage is serious, and the temperature is high, the evaporation is vigorous, so the drought has not been alleviated. In a short week from August 13 to August 17, the total available precipitation is nearly $70 \mathrm{~mm}$ and the soil moisture content increases from $50 \%$ to $80 \%$ of the field water holding capacity. Drought-flood abrupt alternation occurs, and the point of drought-flood abrupt alternation occurs on August 13. According to the calculation, in the drought period of this year, continuous days without available precipitation are as long as 52 days, which belongs to Extraordinary drought. The accumulative available precipitation in the drought period is only $48 \mathrm{~mm}$, which belongs to the transition from Extraordinary drought to moderate flood. Therefore, it is feasible to identify the drought-flood abrupt alternation in tobacco growth period based 
on continuous days without available precipitation and accumulative available precipitation during flood period.

In the tobacco growth period, Guizhou is prone to have droughts and floods, therefore, there may be more than two drought-flood abrupt alternations. According to Figure $3 b$, it can be found that two drought-flood abrupt alternations occurred in 2016, and the abrupt turning point of drought and flood occurred on June 26 and August 2, respectively. The first drought-flood abrupt alternation occurred in the flourishing growing period of tobacco, the number oconsecutive non-effective precipitation days reached 32 days, belonging to heavy drought, the accumulative effective precipitation reached $45 \mathrm{~mm}$ in flood period, belonging to middle flood, with the intensity of abrupt alternation from heavy drought to moderate flood. However, it can be seen from the figure that before and after June 26, the soil moisture content rises from $40 \%$ to $90 \%$ of the field water holding capacity, which is a severe drought-flood abrupt alternation. There is some error in the intensity discrimination, but it can accurately judge the occurrence time of the drought-flood abrupt alternation. The second drought-flood abrupt alternation occurred in the late stage of tobacco maturity, with 35 consecutive days of non-effective precipitation during the drought period, belonging to heavy drought, and the accumulative effective precipitation in the flood period reached $35 \mathrm{~mm}$, belonging to light flood, with the intensity of abrupt alteration from heavy drought to light flood. Before and after August 2, the soil moisture content increased from $40 \%$ to $90 \%$ of field capacity, belonging to the severe drought-flood abrupt alternation. In the drought period, the number of the continuous non-effective precipitation days in the first drought-flood abrupt alternation is almost the same as the cumulative effective precipitation in the flood period. Therefore, in the whole tobacco growth period, it is possible to have many drought-flood abrupt alternations, but the intensity of droughtflood abrupt alternation will not be too high.

\section{Characteristics of drought-flood abrupt alternation in typical years}

The number of days of non-effective precipitation and the accumulative effective precipitation in the flood period during the whole growing period of tobacco in Guiyang from 1951 to 2017 are counted and screened year by year, with the specific screening results shown in Table 3 .

Table 3. characteristics of Drought-Flood Abrupt Alternation in typical years of tobacco growth in Guiyang

\begin{tabular}{|c|c|c|c|c|}
\hline Year & $\begin{array}{l}\text { Continuous days } \\
\text { without available } \\
\text { precipitation (d) }\end{array}$ & $\begin{array}{l}\text { Cumulative effective } \\
\text { precipitation during } \\
\text { waterlogging }(\mathrm{mm})\end{array}$ & Sharp turning degree & $\begin{array}{l}\text { Sharp } \\
\text { turning } \\
\text { point }\end{array}$ \\
\hline \multirow{3}{*}{1957} & 18 & 93 & Light drought turn Severe flood & June 14th \\
\hline & 16 & 158 & Light drought turn Extreme flood & July 28th \\
\hline & 40 & 50.49 & Severe drought turn Light flood & July 6th \\
\hline \multirow[t]{2}{*}{1958} & 18 & 43.03 & Light drought turn Light flood & August 3rd \\
\hline & 14 & 82.62 & Light drought turn Moderate flood & August 23th \\
\hline 1970 & 47 & 228.75 & Extreme drought turn Extreme flood & July 11th \\
\hline 1975 & 72 & 100.98 & Extreme drought turn Severe flood & August 9th \\
\hline 1988 & 48 & 171.02 & Extreme drought turn Extreme flood & August 22th \\
\hline 1991 & 51 & 363.72 & Extreme drought turn Extreme flood & July 9 th \\
\hline 2010 & 52 & 76.58 & Extreme drought turn Moderate flood & August 24th \\
\hline 2016 & 42 & 54.91 & Severe drought turn Light flood & August 4th \\
\hline
\end{tabular}


It can be seen from Table 3 that in the years with severe drought, the number of consecutive non-effective precipitation days is more than 45 days, and the number of consecutive non-effective precipitation days in 1972 is as high as 72 days, from May 28 to August 9, when is flourishing growing period and pre-mature period of tobacco, with the accumulative effective precipitation less than $100 \mathrm{~mm}$, which results in extraordinary drought events, and then within the following 3 days, the accumulative effective precipitation is as high as $100 \mathrm{~mm}$, resulting in heavy flood disaster. In 1957, two drought-flood abrupt alternation occurred, and the abrupt alternation was relatively low. Because of the low intensity of drought in the early period and the high level of flood in the later period, we should focus on preventing the adverse effects of flood in the later period. In the 1970s, two high-intensity drought-flood abrupt alternation occurred, and due to the severe drought in the early period, we did not forget the late flood prevention work while doing the early drought relief work. In the $21^{\text {st }}$ century, the drought degree in the drought period is still serious, and the cumulative effective precipitation in the flood period has been reduced, so we should focus on addressing drought in the early period, especially in the flourishing growing period, when there may be summer drought.

\section{The trend of drought-flood abrupt alternation in different growing periods of tobacco}

Figure 4 shows the trend of drought-flood abrupt alternation in different growing periods of tobacco. (Since the root extension period of tobacco is dominated by waterlogging, and only 4 times of drought-flood abrupt alternation occur, it will not be described here).

Nearly 20 drought-flood abrupt alternations in different degrees occur during the flourishing growing period of tobacco. The duration of drought varies from 20 to 30 days, which is due to excessive cumulative effective precipitation in the root extension period of tobacco, which compensates for the later drought. The cumulative effective precipitation during the flood period is mostly concentrated in 50 100 mm, and the intensity of abrupt alternation is mostly from moderate drought to moderate flood. As can be seen from the change trend curve, during this growing period, the duration of drought increases significantly, and the cumulative effective precipitation in the flood period shows a significant decreasing trend, indicating that the intensity of abrupt alternation is lightening and the drought is increased in the future, when is the critical period of tobacco water demand. Severe drought would make leaves lose water seriously, and the water in the lower leaves is transferred to the upper leaves excessively, causing the lower leaves to wither and form "dry drying". Therefore, the adverse effects of summer drought on tobacco growing should be prevented emphatically.

There are about 25 drought-flood abrupt alternations with varying degree in the premature period of tobacco. The duration of drought fluctuates greatly, because if the accumulative effective precipitation is too much in the flourishing growing period of tobacco, it can compensate for relieving the drought in the later period, and if the tobacco suffers from summer drought in the flourishing growing period, which may aggravate the drought in the later period. The cumulative effective precipitation in flood period is mostly concentrated in the range of $50 \sim 150 \mathrm{~mm}$, and the intensity of abrupt alternation is mostly from heavy drought to heavy flood.

It can be seen from the trend curve that during the growing period of tobacco, the duration of drought has a significant increasing trend, and the cumulative effective precipitation during the flood period has an increasing trend, which indicates an 
increasing trend in the intensity of abrupt alternation in the future. If the tobacco field waterlogging time is too long, resulting in the root oxygen deficiency, it's easy to form "water drying". Therefore, while doing a good job in drought relief, we should pay attention to preventing the adverse effects caused by the drought-flood abrupt alternation.

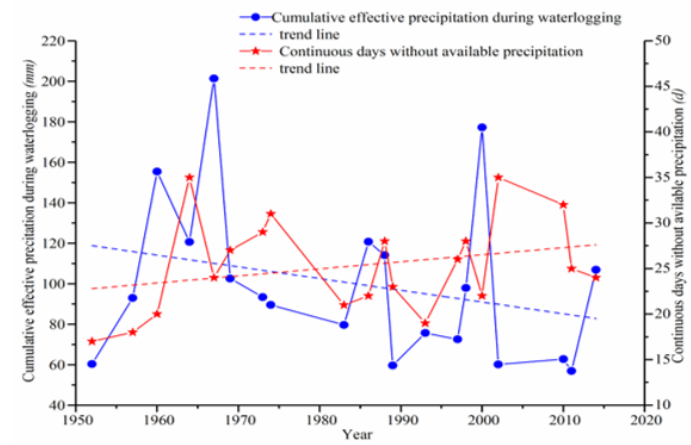

(a) Flourishing growing period of tobacco

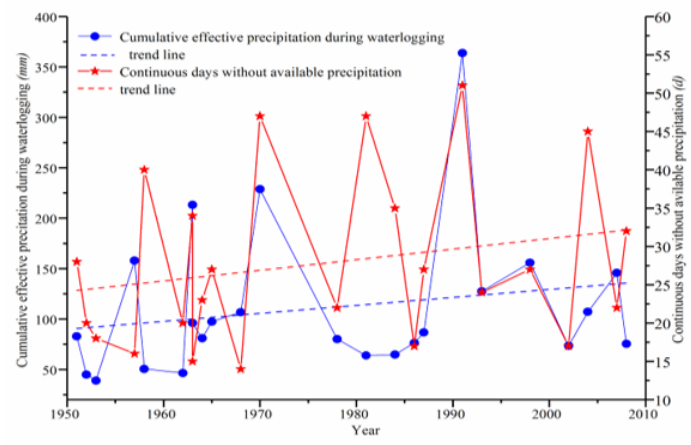

(b) Pre-mature period of tobacco

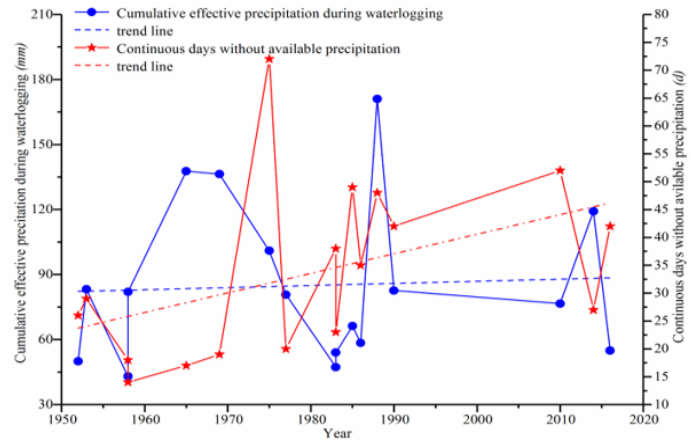

(c) Post-mature period of tobacco

Figure 4. Trend of drought-flood abrupt alternation in different growing periods of tobacco

In the post-mature period of tobacco, there are 15 drought-flood abrupt alternations in different degrees. Before 1970s, the drought lasted about 20 days in the drought period, and after 1980s, the drought lasted about 40 days in the drought period. The cumulative effective precipitation during the flood period is mostly concentrated in $50 \sim 100 \mathrm{~mm}$, and the intensity of abrupt alternation is mostly from heavy drought to moderate flood. According to the changing trend curve, during the growing period, the duration of drought is obviously rising, and the accumulative effective precipitation in flood period is increasing, which indicates that there is an increasing trend in the 
intensity of drought-flood abrupt alternation in the future, and then there is less water demand for tobacco. If the precipitation is too much, the temperature will decrease, the sunshine will weaken, the accumulation of organic matter in the tobacco leaves will decrease, the air humidity will increase, and diseases and pests will easily occur under high temperature. It is important to prevent the adverse effects of flood on tobacco yield and quality.

\section{Discussion}

Guiyang is a typical monsoon climate fragile area, and is extremely prone to drought-flood abrupt alternation because of the monsoon changes, atmospheric circulation anomalies and local unique geographical factors such as geomorphology. The water vapor of heavy rainfall mainly comes from the South China Sea and the Bay of Bengal in the northern Indian Ocean. In the early March-April of the years with drought-flood abrupt alternation, the intensity of the Bay of Bengal monsoon, the East Asian monsoon, the Indian Ocean monsoon and the South China Sea monsoon is all remarkably weak, and the water vapor transport is insufficient, so it is easy to form drought. In summer, the southwest monsoon strengthens and the water vapor transported increases. When the cold air invades, the cold and warm air flow intersects, which is easy to form strong precipitation and cause the drought-flood abrupt alternation. Sun et al. (2017) analyzed the characteristics of atmospheric circulation anomalies, and found that in the early period of the years with drought-flood abrupt alternation, the western Pacific subtropical high is westward strong, the zonal motion of mid-latitude and high-latitude circulation is strong, the upper weaterlies are strong, and the cold air cannot move southward, which is not conducive to precipitation. In the later period, the meridional motion of the mid-latitude and high-latitude circulation is enhanced, the trough beyond the east of Ural Mountains is deepened, the East Asian coastal ridge is strengthened, and the water vapor from southeast and southwest directions is transported to southwest China, resulting in more precipitation in southwest China and the drought-flood abrupt alternation. The terrain in the territory is undulating and blocked by the terrain, the mountain is less exposed to solar radiation in the days, and the air is not as hot as the top of the mountain, causing the air on the top of the mountain to be hot and floating in the sky. The air at the foot of the mountain is cold, and the atmosphere below is relatively stable. In the evening, the temperature at the top of the mountain drops faster than that at the foot of the mountain. The air becomes cooler and then sinks, raising the warm and humid air at the foot of the mountain. The water vapor cools down continuously in the process of air rising, producing heavy rainfall and prone to drought-flood abrupt alternation.

Peng et al. (2018) uses the long and short period drought-flood abrupt alternation index to analyze the characteristics of drought-flood abrupt alternation in Zhengzhou in summer. If this method is used to study the law of drought-flood abrupt alternation in the growing period of tobacco, only the difference of drought and flood in the early and late periods is considered, and the time scale is too large. Only when the whole growing period of tobacco is over, can the degree of drought-flood abrupt alternation be evaluated, which cannot meet the needs of real-time monitoring and early warning evaluation. Chen et al. (2018) used hydrus-1d model to simulate soil moisture movement and study drought-flood abrupt alternation in the growing period of rice. The author thinks that this method not only considers meteorological factors, but also 
considers soil moisture condition and water requirement during the crop growing period, with the certain feasibility. However, the continuous non-effective precipitation days and the accumulative effective precipitation during the flood period can indirectly reflect the income and expense of farmland precipitation and loss of soil moisture, and can accurately describe the law of drought-flood abrupt alternation in the growing period of tobacco. The method does not involve complex operations, and does not require a large number of data to simulate, so it can quickly achieve the monitoring and early warning evaluation of drought-flood abrupt alternation during the growing period of tobacco.

\section{Conclusions}

(1) In this study, the drought index of tobacco growth period constructed by continuous non-effective precipitation days is used to take into account the dual factors of precipitation and precipitation days, which can indirectly reflect the income and expenditure of farmland precipitation and soil moisture profit and loss. The flood index of different growing periods is constructed by using cumulative effective precipitation in the flood period, and the effects of water requirement, flood tolerance and precipitation process on tobacco growth were comprehensively considered. The precipitation and soil moisture data of Xiuwen County Irrigation Experimental Base in 2015 and 2016 are used to verify that the continuous non-effective precipitation days and cumulative effective precipitation in flood period could accurately describe the evolution of drought-flood abrupt alternation in tobacco growth period. It can realize the real-time monitoring and early warning evaluation of the drought-flood abrupt alternation during the growing period of tobacco in this area, and provide scientific basis for timely and accurate disaster prevention and reduction.

(2) In the tobacco root extension period, waterlogging is the main cause. It is easy to suffer from drought-flood abrupt alternation in flourishing period. Guiyang is located in the Yunnan-Guizhou plateau, where there is a severe drought-flood abrupt alternation in the tobacco growing period. In the later stage of maturation drought, the duration of drought increased obviously, and the intensity of drought-flood abrupt alternation increased rapidly, so the adverse effects of flood stress on the yield and quality of tobacco should be prevented.

(3) In the next step, artificial precipitation simulation test of drought and waterlogging is carried out to further improve the accuracy of the coupling method in this paper.

Acknowledgements. This paper is funded by the Water Conservancy Research Project of Guizhou Provincial Water Resources Department (Grant No.: KT201705) and National Natural Science Foundation (Grant No.: 51779093).

\section{REFERENCES}

[1] Bello, A. A., Mamman, M. B. (2018): Monthly rainfall prediction using artificial neural network: A case study of Kano, Nigeria. - Environmental and Earth Sciences Research Journal 5(2): 37-41. 
[2] Cai, H. Y., Wang, Y. W., Li, J. P., Chen, Z. G. (2005): Effect of Soil Water on Configuration and Character of Water Consumption inFlue-cured Tobacco. - Journal of Irrigation and Drainage (3): 38-41.

[3] Chen, C., Hu, T. S., Gao, Y. (2018): Research on the Definition of Drought and Flood Alternation in Rice Irrigation. - China Rural Water and Hydropower (7): 56-61.

[4] Cheng, J. B. (2006): A preliminary Study on Water Requirement character of flued-cured tobacco of high-quality in karst mountain area. - Guizhou University, Guizhou Province.

[5] Dastane, N. G. (1974): Effective rainfall in irrigated agriculture. - Irrigation and Drainage Paper No. 25. New York: Food and Agriculture Organization, United Nations.

[6] Dittus, A. J., Karoly, D. J., Donat, M. G., Lewis, S. C., Alexander, L. V. (2018): Understanding the role of sea surface temperature-forcing for variability in global temperature and precipitation extremes. - Weather and Climate Extremes 21(9): 1-9.

[7] Fan, Y. X. (2018): Catastrophe distinction index of oilseed rape vernal waterlogging and waterlogging impact analysis in Huna. - China Academy of Meteorological Sciences, Beijing.

[8] Gansu Provincial Bureau of Quality and Technical Supervision (2011): Gansu drought Standard DB62/T2034/2011.

[9] Gao, H. J. (2006): Study on Water-saving Irrigation Schedule and Optimum Irrigation Index of Flue-cured Tobacco. - Henan Agricultural University, Henan Province.

[10] Gao, X. R., Wang, C. Y., Zhang, J. Q., Xue, X. Z. (2012): Crop water requirement and temporal-spatial variation of drought and flood disaster during growth stages for maize in Northeast during past 50 years. - Transacti ons of the Chinese Society of Agricultural Engineering 28(12): 101-109.

[11] Gu, X. (2014): Analysis of suitability and climatic characteristics of meteorological drought index in summer in southeastern Guizhou. - 31st Annual meeting of Chinese Meteorological Society, Beijing.

[12] Guizhou Provincial Bureau of quality and Technology Supervision (2015): Guizhou drought standard DB52/T1030-2015.

[13] Han, J. F., Wang, Y. F., Zhang, X. T. (1992): Effects of soil moisture on root development and root activity of flue-cured tobacco. - China Tobacco (3): 14-17.

[14] He, H., Liao, X. P., Lu, H., Chen, S. R. (2016): Features of long-cycle drought-flood abrupt alternation in South China during summer in1961-2014. - Acta GeographicaSinica 71(1): 130-141.

[15] Huang, R. (2015): Research on evolution and Countermeasures of drought-floods abrupt alternation events in Huaihe River basin. - China Institute of Water Resources \& Hydropower Research, Beijing.

[16] Huang, W. H., Sui, Y., Yang, X. G., Dai, S. W., Qu, H. H., Li, M. S. (2014): Spatiotemporal characteristics of crop drought in southern China based on drought index of continuous days without available precipitation. - Transactions of the Chinese Society of Agricultural Engineering 30(4): 125-135.

[17] Huo, Z. G., Wang, S. L. (2009): Agricultural and bio-meteorological disasters. Meteorological Press, Beijing.

[18] IPCC (2013): Climate Change 2013: the Physical Science Basis, Contribution of Working Group I to the Fifth Assessment Report of the Inter-governmental Panel on Climate Change. - Cambridge, United Kingdom and New York, NY, USA: Cambridge University Press, 2013.

[19] Jiang, X. N., Feng, J., Jian, M. Q. (2009): Comparative Analysis of Seasonal Drought Events in Guangzhou With Precipitation and Day without Rain. - Guangdong Meteorology 31(5): 4-5.

[20] Kong, F. (2018): Diagnosis of spatio-temporal pattern changes of global multi-scale rainstorm. - 35th Annual meeting of China Meteorological Society, Anhui Province. 
[21] Li, J. P., Chen, Z. G., Yang, Y. H., Cai, H. Y. (2007): Study on the Adequate Soil Moisture Indexes of Flue-cured Tobacco Irrigation Based on Some Physiological Indexes. - Journal of Irrigation and Drainage 1: 93-96.

[22] Liu, Z. D., Duan, A. W., Xiao, J. F., Gao, Y., Liu, H. (2009): Calculation Model of Effective Precipitation at Growth Stages for Winter Wheat. - Journal of Irrigation and Drainage 28(2): 21-25.

[23] Liu, Y. F., Yuan, Z. H, Guo, L. X., Kong, W., Zhang, L.,Wu, L. (2017): Characteristics of Spatio-Temporal Variation of Abrupt Alternation of Drought and Flood in Shanxi Province During Summers in 1961-2013. - Journal of Ecology and Rural Environment 33(4): 332-340.

[24] Magrini, A., Lazzari, S., Marenco, L., Guazzi, G. (2018): Cost optimal analysis of energy refurbishment actions depending on the local climate and its variations. - Mathematical Modelling of Engineering Problems 5(3): 268-274.

[25] Mesmoudi, K., Meguellati, K., Bournet, P. E. (2017): Thermal analysis of greenhouses installed under semi arid climate. - International Journal of Heat and Technology 35(1): 474-486.

[26] Nocera, F., Gagliano, A., Evola, G., Marletta, L., Faraci, A. (2017): The Kyoto Rotation Fund as a policy tool for climate change mitigation: The case study of an Italian school. International Journal of Heat and Technology 35(S1): S159-S165.

[27] Peng, G. H., Qin, L. L., Ma, J. Q., Huang, M. Y. (2018): Analysis of drought-flood abrupt alternation in Zhengzhou during summer in 1955-2015. - South-to-North Water Transfers and Water Science \& Technology 16(6): 27-32.

[28] Scafetta, N., Mirandola, A., Bianchini, A. (2017): Natural climate variability, part 1: Observations versus the modeled predictions. - International Journal of Heat and Technology 35(S1): S9-S17.

[29] Scafetta, N., Mirandola, A., Bianchini, A. (2017): Natural climate variability, part 2: Interpretation of the post 2000 temperature standstill. - International Journal of Heat and Technology 35(S1): S18-S26.

[30] Shan, L. J., Zhang, L. P., Chen, X. C., Yang, W. (2015): Spatio-temporal Evolution characteristics of Drought-Flood abrupt alternation in the Middle and Lower reaches of the Yangtze River Basin. - Resources and Environment tin the Yangtze Basin 24(12): 2100-2107.

[31] Shan, L. J., Zhang, L. P., Zhang, Y. J., She, D. X. (2018): Characteristics of dry-wet abrupt alternation events in the middle and lowerreaches of the Yangtze River Basin and their relationship with ENSO. - Acta Geographica Sinica 37(1): 25-40.

[32] Sun, X. T., Li, Q. Q., Wang, L. J. (2017): Characteristics of Long-Cycle Abrupt DroughtFlood Alternations in Southwest China and Anomalies of Atmospheric Circulation in Summer. - Chinese Journal of Atmospheric Sciences 41(6): 1332-1342.

[33] Tang, S. K. (2011): The environment of tobacco growth. - Yun Yunnan Science and Technology Publishing Press, Yunnan Province.

[34] Uttam, P., Goswami, B., Hazra, M. K. (2018): Copula-based probabilistic characterization of precipitation extremesover North Sikkim Himalaya. - Atmospheric Research 212(11): 273-284.

[35] Wang, N., Wang, Q., Fang, F., Cai, X. L., Xiao, K. L., Fang, J. G. (2014): Characteristics of spatial and temporal variation of extreme no rain days in each season in Shaanxi province. - Agricultural Research in the Arid Areas 32(6): 221-228, 267.

[36] Wu, Z. W., Li, J. P., He, J. H., Jiang, Z. H. (2006): Occurrence of droughts and floods during the normal summer monsoons in the mid and lower reaches of the Yangtze River. - Geophysical Research Letters 33(5): 813.

[37] Xu, F. Q. (2009): Concise analysis of effective precipitation. - Meteorological, Hydrological and Marine Instruments 26(1): 96-100. 
[38] Yang, H. Y., Huo, Z. G., Yang, J. Y., Zhang, G. X., Wu, L., Fan, Y. X. (2017): Indicators and Risk o f Spring Corn Waterlogging Disaster in Jianghan and West Region of Jiangnan. - Journal of Applied Meteorological Science 28(2): 237-246.

[39] Zhao, G. Y., Han, Y., Liu, M. H., Hou, J. L., Shi, H. P., Liu, W. Z., Guo, Y. L., Qiao, Q. (2018): Spatial-temporal Variation of Extreme Precipitation Events in Henan Province from 1961 to 2013. - Research of Soil and Water Conservation 25(6): 115-120. 